\title{
Visible and shortwave near infrared spectroscopy for predicting sugar content of sugarcane based on a cross-sectional scanning method
}

\begin{abstract}
The need for a reliable in-field quality measurement in the sugarcane industry is growing as the quality of sugarcane could vary significantly across the field. However, current monitoring systems in this industry only monitor crop yield and do not have the ability to measure the product quality. Thus, the potential of the visible/shortwave near infrared (vis/SW-NIR) spectroscopic technique as a low-cost alternative to predict sugar content from sugarcane stalks was investigated. Two hundred and ninety-two internode samples were extracted from three different sugarcane varieties to assess the ability of this technique. Each sample was cut into four sections and the spectra collected from the cross-sectional surface of each section were later correlated with its sugar content ( ${ }^{\circ}$ Brix). Partial least square (PLS) models were developed using calibration samples. The best model predicted samples in a prediction set had a coefficient of determination (r2) of 0.87 and root means square error of prediction (RMSEP) of $1.45^{\circ}$ Brix. The value of the ratio of the standard deviation to the standard error of prediction (RPD) was 2 . The variations of ${ }^{\circ}$ Brix and prediction accuracy along the individual internode were 8.7 and $13 \%$, respectively. These results indicated the vis/SW-NIR spectroscopy could be applied to predict ${ }^{\circ}$ Brix values from sugarcane stalks based on a cross-sectional scanning method.
\end{abstract}

Keyword: Sugarcane; Sugar content; ${ }^{\circ}$ Brix; Internode; Visible-shortwave near infrared spectroscopy 